\title{
MOISTURE SUSCEPTIBILITY OF ASPHALT MIXTURE AND EFFECTIVENESS OF ANTI- STRIPPING ADDITIVE
}

\author{
Peiwen $\mathrm{HAO}^{1}$ and Yoshitaka HACHIYA ${ }^{2}$ \\ ${ }^{1}$ Dr. Eng., Postdoctoral fellow of Japan Society for the Promotion of Science (JSPS), National Institute for \\ Land and Infrastructure Management (NILIM), Ministry of Land, Infrastructure and Transport (MOLIT) \\ (1-1, Nagase 3, Yokosuka, 239-0826, Japan) \\ E-mail: hao-p92y2@ysk.nilim.go.jp \\ ${ }^{2}$ Member of JSCE, Dr. Eng., Head of Airport Facility Division, Airport Research Department, NILIM, MOLIT \\ (1-1, Nagase 3, Yokosuka, 239-0826, Japan) \\ E-mail: hachiya@ipc.ysk.nilim.go.jp
}

\begin{abstract}
A series of laboratory tests was conducted to evaluate the moisture susceptibility of asphalt mixtures, including moisture damage of asphalt-aggregate bond, and the influence of water immersion on the properties of asphalt mixtures. Furthermore, the effectiveness of various anti-stripping additives was investigated through a variety of tests. It was found that both the asphalt and aggregate types have dominating influences on the moisture susceptibility of asphalt mixtures; hydrated lime slurry is an effective anti-stripping additive for improving the moisture susceptibility; and the net adsorption test, Lottman test and immersed wheel tracking test are effective tools to evaluate the moisture susceptibility.
\end{abstract}

Key Words: asphalt mixture, moisture susceptibility, laboratory test, asphalt acid value, anti-stripping additive

\section{INTRODUCTION}

Damage to asphalt mixtures by water is one kind of asphalt pavement failure. The moisture damage occurs in two ways, softening and stripping; the former is characterized by a loss of cohesion, which reduces the strength and stiffness of the asphalt mixture, whereas the latter involves a loss of adhesion and physical separation of asphalt and aggregate ${ }^{1)}$. In the latter case, which has a greater influence on the pavement performance, adhesion of asphalt deteriorates, asphalt film segregates from the aggregate surface, and finally raveling of the asphalt mixture and potholes generally appear.

This moisture susceptibility of asphalt mixture is related to the aggregate properties, asphalt properties and film thickness, interaction between asphalt and aggregate, air void of asphalt mixture, and traffic ${ }^{2)}$. Among these, the interaction between asphalt and aggregate is the main factor influencing the stripping of asphalt mixtures, so it is very important to analyze it.

Through chemisorption, which is the process of forming an adsorptive layer in the surface of aggregate through chemical reaction between acidic media in asphalt and cationic media on the surface of aggregate, adhesion between asphalt and aggregate generally becomes larger than physical adsorption, and so the asphalt mixture has much greater moisture resistance ${ }^{3}$. The effectiveness of chemisorption, that is, the adhesion between asphalt and aggregate, depends on the chemical composition of asphalt and aggregate ${ }^{4)}$; for example, asphaltic acid and asphaltic acid anhydride in asphalt make chemical adsorption with high valency charge media salt from the aggregate. The surface active composition in asphalt can be ranked according to activity as follows: asphaltic acid > asphaltic acid anhydride $>$ resin $>$ oil. Thus, the influence of acid materials in asphalt on the adhesion between asphalt and aggregate should be examined further. 
The potential for asphalt mixtures to suffer moisture damage can be controlled or reduced through material selection, mixture design that includes high asphalt film thickness and usage of additives, pavement design, construction and drainage ${ }^{5), 6)}$.

The aggregates and asphalt for mixtures susceptible to stripping can be treated with a variety of anti-stripping additives; these additives commonly include the following:

- Liquid anti-stripping additives

These materials, which are commercially available under various trade names and designations, are used as additives to asphalt. They are easy to handle from a construction standpoint and have been used for a number of years. Their usefulness is, however, somewhat uncertain because of heat stability problems ${ }^{7}$.

- Portland cement

Portland cement is added to aggregates. Though it has been reported to be generally effective, it has not been used widely.

- Hydrated lime

Hydrated lime is normally added to aggregates and has been used widely in many countries. The use of lime as an anti-stripping chemical has long been recognized, and recent researches and field observations have confirmed its usefulness. Many researches indicate that the most efficient method of applying lime is in the form of slurry placed on the surface of aggregates ${ }^{8), 9 \text { ). }}$

While hydrated lime is considered as an effective additive to minimize moisture damage, many liquid anti-stripping additives are also recognized to be acceptable and in many cases appear to be equal or better than hydrated lime. It was reported recently that the indirect tensile strength and tensile strength ratio (TSR) for mixtures with liquid anti-stripping additives were not significantly different from those of mixtures containing aggregates fully coated with hydrated lime, mixtures with hydrated lime showed no superiority over those with liquid anti-stripping additives, based on TSR values at several overlay sections containing various anti-stripping additives, and liquid anti-stripping additives can be used as a substitute for hydrated lime without sacrificing moisture resistance ${ }^{10)}$. Thus, the effect of antistripping additives should be examined in detail.

In this study, we examined the fundamental properties of asphalt-aggregate interactions, including adsorption and moisture damage by various test methods, and the influence of asphalt acid value on moisture susceptibility of asphalt mixture. We also investigated the effectiveness of hydrated lime and other selected anti-stripping additives through various tests, and then evaluated suitable methods to clarify the moisture susceptibility of asphalt mixture.

\section{SCOPE OF STUDY}

\section{(1) Study plan}

In the study on the influence of asphalt acid value on water susceptibility of asphalt mixture, various asphalt mixtures were prepared by using five kinds of asphalt from different crude oil and three kinds of aggregate with different chemical properties.

Two kinds of laboratory test were conducted. One was a series of tests for clarifying the ease of asphalt stripping between asphalt and aggregate, including the water immersion test, electro-optic colorimetry test, and net adsorption test. The other was a series of tests for investigating the change of mechanical properties of asphalt mixture due to water immersion, in which the retained Marshall stability test and Lottman test were conducted.

In the study on the effectiveness of anti-stripping additives for preventing water damage in asphalt mixture, three kinds of anti-stripping additive were used together with a kind of asphalt and three kinds of aggregates.

In this study, the changes of mechanical properties of asphalt mixtures due to water immersion were investigated through laboratory tests. In addition to the aforementioned retained Marshall stability test and Lottman test, the water immersed wheel tracking test was also performed.

Furthermore, the stability of asphalt mixtures treated with anti-stripping additives under the aged condition was evaluated through the Lottman test and the retained Marshall stability test. Two aging methods, that is, short-term aging and long-term aging, were used for asphalt mixtures with limestone aggregates.

\section{(2) Materials \\ a) Asphait}

Five kinds of asphalt were used in the study on the influence of asphalt on the moisture susceptibility of asphalt mixture. They were commercially produced in different asphalt refineries with different crude oil and were herein denoted as KL, LH, MM, SJ and SL after the refinery. Their properties, including both physical and chemical properties, are shown in Table 1. As a chemical property, the asphalt acid value was 
Table 1 Properties of asphalts

\begin{tabular}{c|c|c|c|c|c}
\hline \multicolumn{2}{c}{ a) Original } \\
\hline Item & KL & LH & MM & SJ & SL \\
\hline Density $\left(15^{\circ} \mathrm{C}\right), \mathrm{g} / \mathrm{cm}^{3}$ & 0.9815 & 1.005 & 1.013 & 0.9978 & 1.001 \\
Solution, \% & 99.10 & 99.53 & 99.91 & 99.08 & 99.78 \\
Wax content, \% & 1.28 & 3.85 & 4.08 & 4.19 & 5.55 \\
Flash point, ${ }^{\circ} \mathrm{C}$ & 300 & 280 & 350 & 320 & 296 \\
Fraass breaking point, ${ }^{\circ} \mathrm{C}$ & -15 & -19.8 & -13 & -14.8 & -16.7 \\
Softening point, ${ }^{\circ} \mathrm{C}$ & 49.5 & 46 & 50 & 50.5 & 49 \\
Penetration $\left(25^{\circ} \mathrm{C}\right), 1 / 10 \mathrm{~mm}$ & 89 & 138 & 81 & 97 & 96 \\
PI & 0.19 & -1.43 & -0.8 & -1.07 & -1.69 \\
Ductility $\left(15^{\circ} \mathrm{C}\right), \mathrm{cm}$ & $>150$ & $>150$ & $>100$ & 58 & 22 \\
Viscosity $\left(60^{\circ} \mathrm{C}\right), \mathrm{pa} \cdot \mathrm{s}$ & 309.9 & 65 & 129.1 & 62.4 & 59.3 \\
Acid value, $\mathrm{ml} \cdot \mathrm{mol} / \mathrm{L} / \mathrm{g}$ & 2.510 & 1.256 & 0.273 & 1.789 & 0.564 \\
\hline
\end{tabular}

b) After thin film oven test (TFOT)

\begin{tabular}{c|c|c|c|c|c}
\hline Item & KL & LH & MM & SJ & SL \\
\hline Weight loss, \% & -0.05 & -0.20 & 0.15 & -0.06 & 0.10 \\
Softening point, ${ }^{\circ} \mathrm{C}$ & 51.5 & 48.5 & 52 & 53 & 52 \\
Penetration ratio, \% & 75.2 & 60.9 & 66.7 & 60.8 & 64.6 \\
Ductility $\left(15^{\circ} \mathrm{C}\right), \mathrm{cm}$ & $>100$ & 43.6 & 29.8 & 12.8 & 6.8 \\
\hline
\end{tabular}

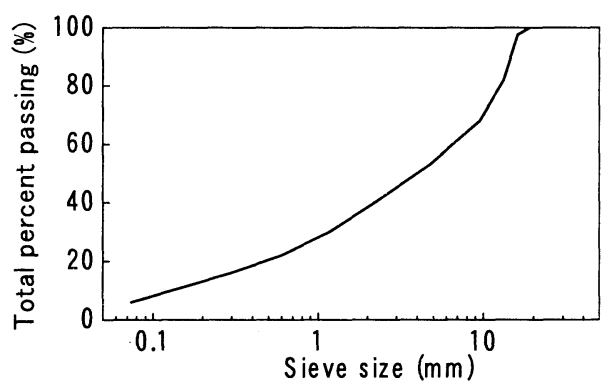

Table 2 Physical properties of aggregates

\begin{tabular}{c|c|c|c}
\hline Aggregate & $\begin{array}{c}\text { Specific gravity, } \\
\mathrm{g} / \mathrm{cm}^{3}\end{array}$ & $\begin{array}{c}\text { Absorption, } \\
\%\end{array}$ & $\begin{array}{c}\mathrm{SiO}_{2} \text { content, } \\
\%\end{array}$ \\
\hline Granite & 2.751 & 0.43 & 76.5 \\
Schist & 2.834 & 0.49 & 63.1 \\
Limestone & 2.712 & 0.51 & 6.5 \\
Filler & 2.745 & - & - \\
\hline
\end{tabular}

Figure 1 Central value of specified aggregate gradations<smiles>[R]C(=O)NCCNCCNCCNCCNN</smiles>

a) AST-3

Figure 2 Chemical constituents of additives<smiles>[R]NCCCN[Y]</smiles>

b) PA-1 measured based on reference 11); the asphalt acid value was ranked as $\mathrm{KL}>\mathrm{SJ}>\mathrm{LH}>\mathrm{SL}>\mathrm{MM}$.

$\mathrm{KL}$ asphalt was widely used in China and was also used in the study on anti-stripping additive to generalize the results.

\section{b) Aggregate}

Three kinds of aggregates were used in asphalt mixtures: limestone, granite and schist, the chemical property of which is characterized as basic, acidic, neutral, respectively. Granite has a history of producing water-susceptible asphalt mixture, whereas limestone has good stripping resistance in asphalt mixture.

The central value of the specified gradation and physical properties of these aggregates are shown in Figure 1 and Table 2, respectively.

\section{c) Additives}

Four kinds of anti-stripping additives were evaluated: Portland cement, hydrated lime, and two liquid anti-stripping additives.

The Portland cement and hydrated lime were added in the ratio of $1 \%$ of aggregate by mass. Two liquid anti-stripping additives, named AST-3 and PA-1 (commercially available product), were used, the chemical constituents of which are shown in Figure 2. The contents were $0.3 \%$ of asphalt by mass. 
Table 3 Anti-stripping additives

\begin{tabular}{c|c|c}
\hline ID & Additive & Amount \\
\hline A & Portland cement & $1 \%$ of aggregates \\
B & Hydrated lime & $1 \%$ of aggregates \\
C & Lime slurry & $1 \%$ of aggregates \\
D & AST-3 & $0.3 \%$ of asphalt \\
E & PA-1 & $0.3 \%$ of asphalt \\
F & No & - \\
\hline
\end{tabular}

There were two methods of introducing lime into asphalt mixture:

i) Dry lime was added to cold aggregates and mixed well to coat the aggregates, and then they were heated before mixing with asphalt.

ii) Lime, combined with water in the proportion of 7 to 3, was mixed with cold aggregates and they were dried at $130^{\circ} \mathrm{C}$ for at least 15 hours before mixing with asphalt.

Portland cement was introduced by the dry lime treatment method.

Liquid anti-stripping additives were added to asphalt preheated to about $140^{\circ} \mathrm{C}$ and they were continuously stirred to ensure homogeneity before mixing with aggregates.

Table 3 summarizes the anti-stripping additives used. The identifications given in the table are used in the following figures.

\section{d) Asphalt mixture}

The asphalt mixture was designed in principle by following the standard Marshall method specified for road pavement: 75 blows on both sides of the specimen in preparation and a Marshall stability of $7.5 \mathrm{kN}$. For asphalt mixtures used to study moisture susceptibility, the asphalt content of $5 \%$, which was not the optimum asphalt content for all the mixtures, was fixed to eliminate the effect of asphalt content on the properties of asphalt mixtures. However, the optimum asphalt content of $4.8 \%$ was adopted for those used to study the effect of anti-stripping additives, but was not adjusted for the presence or absence of additives.

\section{(3) Test methods}

\section{a) Stripping resistance of asphalt-aggregate bond}

The following three kinds of tests were performed.

\section{- Water immersion test}

This test visually determines the extent of stripping of asphalt from aggregate surfaces after the asphalt mixture is immersed in water for a specified time in accordance with JHS $201^{12}$. The extent of stripping, namely stripping ratio, is quantified as the percentage of asphalt lost in the mixture during water immersion.

- Electro-optic colorimetry test

This test quantifies the stripping susceptibility of asphalt-aggregate by measuring the difference in phenol safranine dyestuff solution after both aggregate and asphalt-aggregate are soaked. In the test, clean aggregates of $2.5-5 \mathrm{~mm}$ in diameter mixed with asphalt and pure aggregates are immersed separately into phenol safranine dyestuff solution at $60^{\circ} \mathrm{C}$ for two hours. Then, the concentration is measured using spectrophotometer at the wavelength of $510 \mathrm{~nm}$. The test method substantially follows the general solution analytical technique described in reference 3 ), for instance.

The stripping ratio is calculated as $q^{\prime} / q$ ( $q$ : pure aggregate adsorption (mg/g) and $q^{\prime}$ : asphaltaggregate adsorption).

- Net adsorption test

The test determines the affinity between asphalt and aggregate (initial adsorption) and the moisture sensitivity of the asphalt-aggregate bond (net adsorption), by using asphalt-toluene solution, as specified by SHRP M-001 ${ }^{13}$. The initial adsorption is determined from the difference in concentration of asphalt-toluene solution before and after contact with aggregates. The net adsorption is also determined from the difference in concentration of asphalt-toluene solution before and after contact with aggregates together with water immersion. The stripping ratio is calculated in the same way as mentioned above.

In the electro-optic colorimetry test, the phenol safranine dyestuff can soak into the interface between aggregate and asphalt, and the asphalt film is not peeled away but separated from the aggregate surface. In contrast, the asphalt film might be peeled away from the aggregate surface in other tests.

b) Influence of water on asphalt mixture properties

Three types of tests were used to evaluate the influence of water immersion on the mechanical properties of asphalt mixtures, as follows.

- Retained Marshall stability test

The retained Marshall stability $\left(S_{0}\right)$ is calculated as the ratio of Marshall stability of specimen soaked in water for forty-eight hours at $60^{\circ} \mathrm{C}\left(S_{1}\right)$ to that soaked in water for two hours at $60^{\circ} \mathrm{C}\left(S_{2}\right)$, specified by JHS 202 .

- Lottman test

Indirect tensile strength is used. Moisture susceptibility is determined by the ratio of indirect tensile strength in the wet condition $\left(R_{2}\right)$ to that in the dry condition $\left(R_{1}\right)$ as the tensile strength ratio (TSR), in accordance with AASHTO T283. 
Table 4 Stripping ratio in water immersion test

\begin{tabular}{c|c|c|c|c|c}
\hline Aggregate & KL & LH & MM & SJ & SL \\
\hline Granite & 50 & 65 & 55 & 60 & 70 \\
Limestone & 5 & 5 & 15 & 5 & 15 \\
Schist & 15 & 20 & 35 & 20 & 70 \\
\hline \multicolumn{4}{c}{ (unit: \%) }
\end{tabular}

Table 5 Stripping ratio in electro-optic colorimetry test

\begin{tabular}{c|c|c|c|c|c}
\hline Aggregate & KL & LH & MM & SL & SJ \\
\hline Granite & 35.6 & 85.3 & 57.4 & 96.7 & 54.9 \\
Limestone & 22.2 & 72.6 & 39.2 & 64.7 & 43.1 \\
Schist & 48.7 & 64.3 & 42.9 & 84.4 & 34.6 \\
\hline
\end{tabular}

(unit: \%)

Table 6 Stripping ratio in net adsorption test

\begin{tabular}{c|c|c|c|c|c|c|c|c|c}
\hline Asphalt & \multicolumn{3}{|c|}{ Granite } & \multicolumn{3}{c|}{ Limestone } & \multicolumn{3}{c}{ Schist } \\
& $\begin{array}{c}\text { Initial } \\
\text { adsorption }\end{array}$ & $\begin{array}{c}\text { Net } \\
\text { adsorption }\end{array}$ & $\begin{array}{c}\text { Stripping } \\
\text { ratio }\end{array}$ & $\begin{array}{c}\text { Initial } \\
\text { adsorption }\end{array}$ & $\begin{array}{c}\text { Net } \\
\text { adsorption }\end{array}$ & $\begin{array}{c}\text { Stripping } \\
\text { ratio }\end{array}$ & $\begin{array}{c}\text { Initial } \\
\text { adsorption }\end{array}$ & $\begin{array}{c}\text { Net } \\
\text { adsorption }\end{array}$ & $\begin{array}{c}\text { Stripping } \\
\text { ratio }\end{array}$ \\
\hline KL & 0.0618 & 0.0153 & 75.2 & 0.0834 & 0.0770 & 8.0 & 0.2252 & 0.1182 & 19.7 \\
LH & 0.0318 & 0.0127 & 60.1 & 0.8055 & 0.0697 & 15.5 & 0.1949 & 0.1223 & 37.9 \\
MM & 0.0469 & 0.0094 & 79.9 & 0.1080 & 0.0685 & 30.3 & 0.1391 & 0.0529 & 62.0 \\
SJ & 0.1196 & 0.0490 & 58.9 & 0.1057 & 0.0799 & 17.0 & 0.1732 & 0.1366 & 21.2 \\
SL & 0.0097 & 0.0 & 100.0 & 0.1565 & 0.1069 & 31.1 & 0.1432 & 0.0606 & 57.7 \\
\hline
\end{tabular}

(unit: original adsorption-mg/g, net adsorption-mg/g, striping ratio-\%)

Table 7 Criteria on moisture susceptibility ${ }^{14)}$

Stripping ratio (\%) Asphalt-aggregate adhesion

\begin{tabular}{c|c}
$<30$ & Good \\
$45-30$ & Marginal \\
$>45$ & Poor
\end{tabular}

- Immersed wheel tracking test

The wheel tracking test is performed on the specimen immersed in water at $60^{\circ} \mathrm{C}$ for forty-eight hours. The stripping index (SI) is calculated as the ratio of the loss of mass during the test to the mass before the test.

Two aging methods, which are partly applied before preparing the specimens for the abovementioned tests, are as follows:

- Short-term aging method

Loose asphalt mixture with an even thickness of $25-50 \mathrm{~mm}$ is placed in a forced-draught oven at $135^{\circ} \mathrm{C}$ for four hours, stirred every hour, and then the specimens are prepared for the tests.

- Long-term aging method

Specimens are prepared by using asphalt mixtures aged briefly in the above-mentioned way and placed in an oven at $85^{\circ} \mathrm{C}$ for 120 hours before the tests.

\section{WATER SUSCEPTIBILITY ASPHALT MIXTURES}

This section reveals the properties of asphaltaggregate interactions and the influence of asphalt acid value on moisture susceptibility of asphalt mixtures through various tests.

\section{(1) Stripping resistance of asphalt-aggregate bond}

The results of the water immersion test are shown in Table 4. The stripping, ratio depends on both the type of aggregates and the type of asphalt. Whereas limestone showed good resistance against stripping, granite was very susceptible to stripping. From the viewpoint of stripping resistance, asphalt is ranked as $\mathrm{KL}>\mathrm{SJ}>\mathrm{LH}>\mathrm{MM}>\mathrm{SL}$.

The results of the electro-optic colorimetry test are shown in Table 5. The influence of both the type of aggregate and the type of asphalt on the moisture susceptibility of asphalt mixtures is similar to that in the water immersion test.

The results of the net adsorption test are shown in Table 6, indicating a similar trend to moisture susceptibility. The chemical properties of aggregates play a significant role in determining the strength of bond; the stripping ratio ranges from 8.0 to $31.3 \%$ with limestone, from 19.7 to $62.0 \%$ with schist and from 58.9 to $100 \%$ with granite.

According to the criteria on moisture susceptibility of asphalt-aggregate adhesion suggested by SHRP as shown in Table 7, limestone is evaluated to have superior stripping resistance, and schist is also evaluated to have marginally higher stripping resistance than granite.

The types of asphalt also have a large influence on moisture susceptibility. Whereas KL, LH and SJ asphalts appear to have higher stripping resistance, MM and SL asphalts appear to have lower stripping resistance.

The stripping ratios measured in these three tests are plotted against asphalt acid value, which represents the chemical properties of asphalt, in Figures 3, 4 and 5. These figures show that the 
Table 8 Retained Marshall stability

\begin{tabular}{|c|c|c|c|c|c|c|c|c|c|}
\hline \multirow{2}{*}{ Asphalt } & \multicolumn{3}{|c|}{ Granite } & \multicolumn{3}{|c|}{ Limestone } & \multicolumn{3}{|c|}{ Schist } \\
\hline & $S_{1}$ & $S_{2}$ & $S_{0}$ & $S_{1}$ & $S_{2}$ & $S_{0}$ & $S_{1}$ & $S_{2}$ & $S_{0}$ \\
\hline $\mathrm{KL}$ & 10.63 & 6.42 & 63.5 & 8.27 & 7.87 & 90.3 & 10.61 & 7.88 & 74.3 \\
\hline LH & 10.12 & 4.40 & 43.4 & 7.99 & 7.41 & 89.4 & 11.74 & 6.42 & 54.7 \\
\hline MM & 10.70 & 0 & 0 & 10.63 & 8.01 & 79.9 & 11.95 & 2.94 & 24.6 \\
\hline SJ & 10.11 & 6.46 & 63.9 & 8.96 & 7.28 & 81.3 & 10.96 & 8.03 & 73.3 \\
\hline SL & 10.39 . & 2.16 & 20.8 & 8.83 & 7.82 & 88.5 & 11.98 & 5.28 & 44.1 \\
\hline
\end{tabular}

Table 9 Tensile strength ratio in Lottman test

\begin{tabular}{c|c|c|c|c|c|c|c|c|c}
\hline \multirow{2}{*}{ Asphalt } & \multicolumn{3}{|c|}{ Granite } & \multicolumn{3}{c|}{ Limestone } & \multicolumn{3}{c}{ Schist } \\
\cline { 2 - 10 } & $R_{1}$ & $R_{2}$ & TSR & $R_{1}$ & $R_{2}$ & TSR & $R_{1}$ & $R_{2}$ & TSR \\
\hline KL & 0.564 & 0.217 & 38.5 & 0.465 & 0.450 & 96.8 & 0.482 & 0.353 & 73.2 \\
LH & 0.515 & 0.158 & 30.7 & 0.516 & 0.394 & 75.4 & 0.527 & 0.250 & 47.4 \\
MM & 0.621 & 0.077 & 12.1 & 0.671 & 0.385 & 57.4 & 0.637 & 0.092 & 14.8 \\
SJ & 0.624 & 0.210 & 33.7 & 0.483 & 0.429 & 88.8 & 0.638 & 0.364 & 57.1 \\
SL & 0.576 & 0.037 & 6.4 & 0.459 & 0.351 & 76.5 & 0.616 & 0.173 & 28.1 \\
\hline
\end{tabular}

(unit: $R_{1}, R_{2}-\mathrm{MPa}$, TSR-\%)

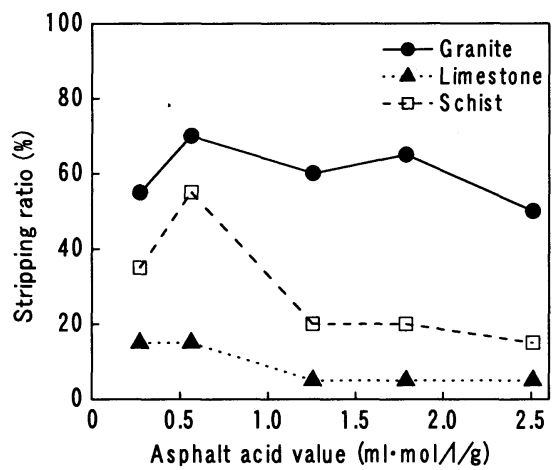

Figure 3 Acid value and stripping ratio in water immersion test

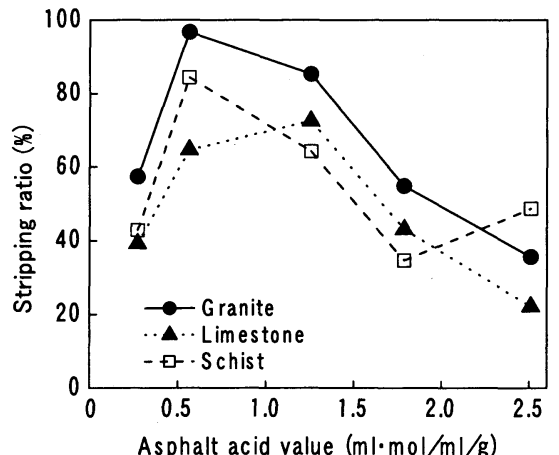

Figure 4 Acid value and stripping ratio in electro-optic colorimetry test

stripping ratios decrease as the asphalt acid value increases. As the water immersion test involved visual observation, the results may contain significant errors. The electro-optic colorimetry test, which has disadvantages such that the stripping ratio

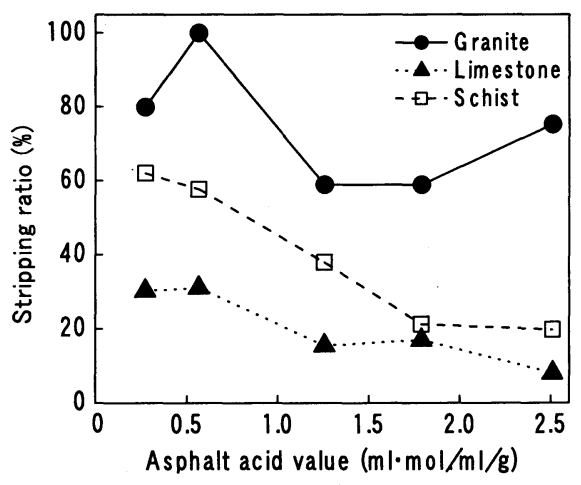

Figure 5 Acid value and stripping ratio in net adsorption test

does not clearly differ among the asphalt mixtures, might show the separation ratio of asphalt film from the aggregate surface.

In contrast, the net adsorption test evaluates asphalt adsorption from the aggregate surface by directly measuring changes in the concentration of asphalt solution, and so can reduce the error. Thus, this method is suitable for evaluating the moisture susceptibility of asphalt-aggregate bond.

\section{(2) Mechanical properties of asphalt mixtures}

The results of the retained Marshall stability test are shown in Table 8. Of the aggregates, limestone has superior moisture stability, whereas granite has the lowest moisture stability. The moisture stability of the asphalt mixture with limestone, which is influenced by asphalt type, is ranked as $\mathrm{KL}>\mathrm{LH}>\mathrm{SL}>\mathrm{SJ}>\mathrm{MM}$, and the stability with other aggregates is similar to this.

The results of the Lottman test are shown in 


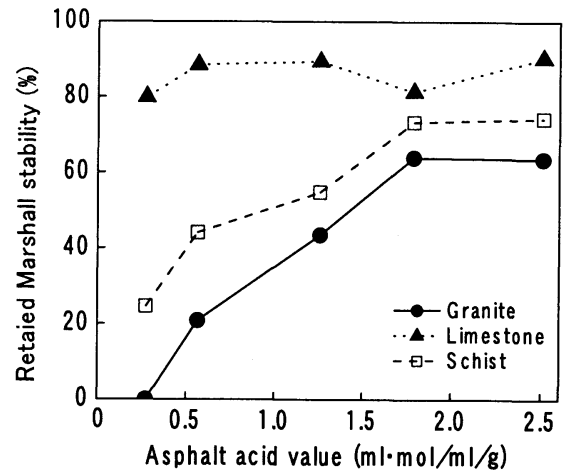

Figure 6 Asphalt acid value and retained Marshall stability

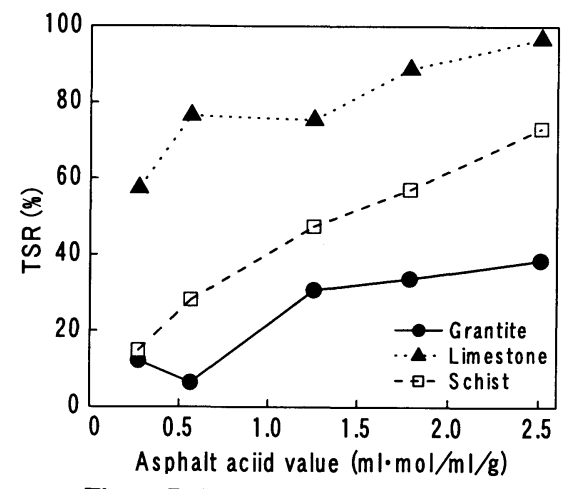

Figure 7 Asphalt acid value and TSR

Table 9. The influence of aggregate type on the moisture susceptibility is the same as that in the retained Marshall stability test. According to the recommendation ${ }^{15)}$, the asphalt mixture with limestone, having TSR of $70 \%$ or more, meets the specification except for MM asphalt, but the mixtures with other aggregates do not meet the specification. The asphalt mixture with $\mathrm{KL}$ asphalt has the highest moisture stability, whereas those with MM and SL asphalt have the lowest.

The relationship between asphalt acid value and moisture susceptibility of asphalt mixture is shown in Figures 6 and 7.

Figure 6 shows that the retained Marshall stability increases with asphalt acid value and depends on the type of aggregate. These trends are similar to those for asphalt-aggregate bond. As the retained Marshall stability of asphalt mixture with limestone scarcely changes with asphalt acid value, the retained Marshall stability test could hardly distinguish the moisture susceptibility in all the aggregate cases.

In Figure 7, TSR of the asphalt mixture with limestone increases with asphalt acid value. Thus, the Lottman test is suitable for evaluating the moisture susceptibility of asphalt mixtures.

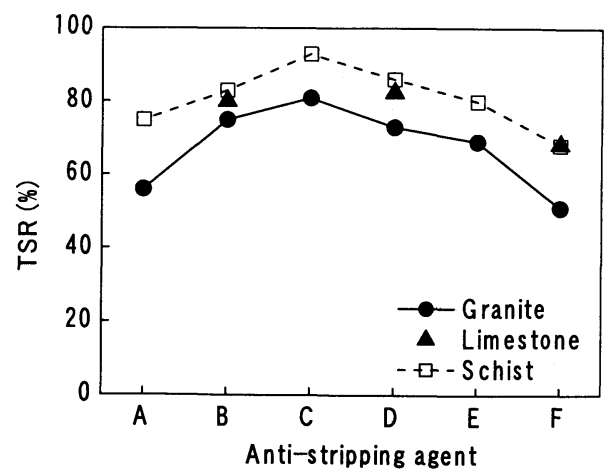

Figure 8 Anti-stripping additives and TSR

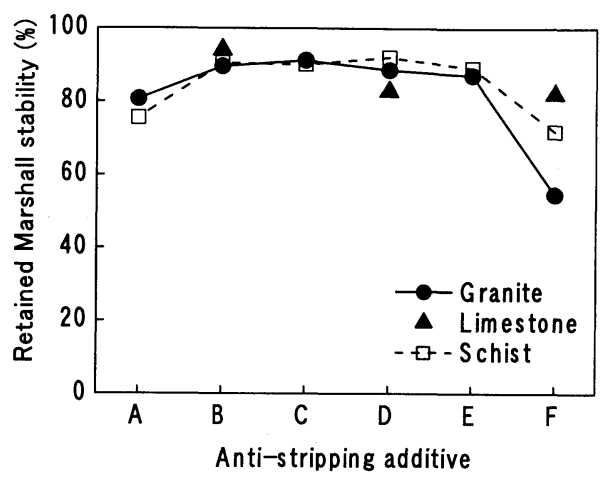

Figure 9 Anti-stripping additive and retained Marshall stability

\section{EFFECT OF ADDITIVES ON MOISTURE SUSCEPTIBILITY}

This section clarifies the effect of anti-stripping additives on the moisture susceptibility by a series of laboratory tests, and ensures the applicability of additives for actual construction through two aging methods.

\section{(1) Property changes due to water immersion}

As shown in Figure 8, the results of the Lottman test show that all the anti-stripping additives improve the moisture susceptibility of asphalt mixtures and the degree of improvement depends on both the additive and aggregate types.

From the figure, it is found that the lime slurry (C) has the highest resistance to moisture damage and hydrated lime (B) and liquid anti-stripping additive AST-3 (D) also have good moisture stability. However, Portland cement (A) slightly improves the moisture susceptibly of asphalt mixture. In addition, the aggregate strongly influences the moisture stability after adding the additives; that is, TSR of the asphalt mixture with granite never exceeds that of mixtures with other aggregates. 


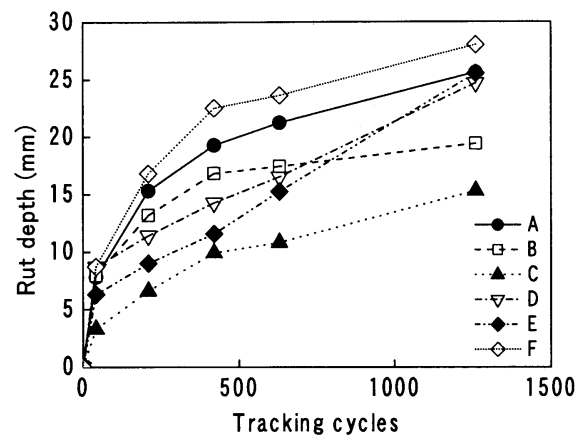

Figure 10 Rut depth with tracking cycles (Granite)

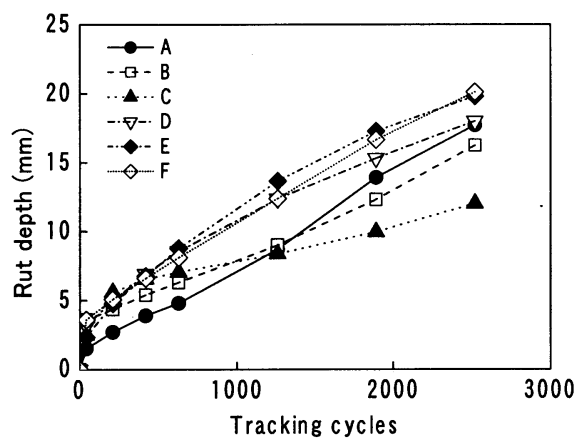

Figure 11 Rut depth with tracking cycles (Schist)

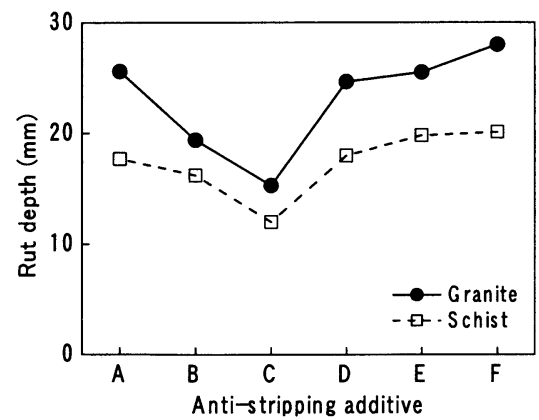

Figure 12 Anti-stripping additive and rut depth

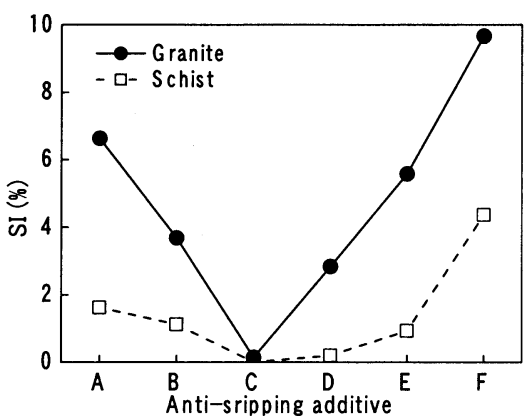

Figure 13 Anti-stripping additive and SI

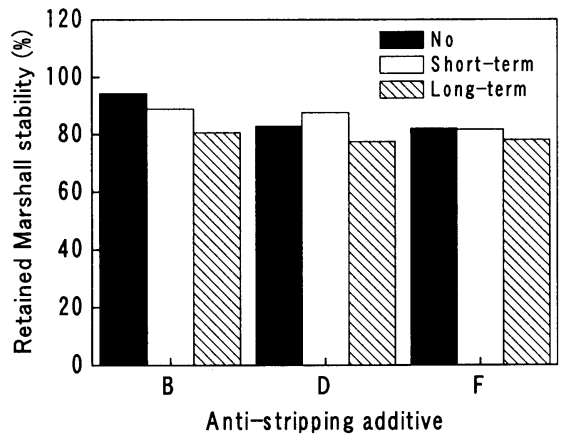

Figure 14 Influence of aging on retained Marshall stability

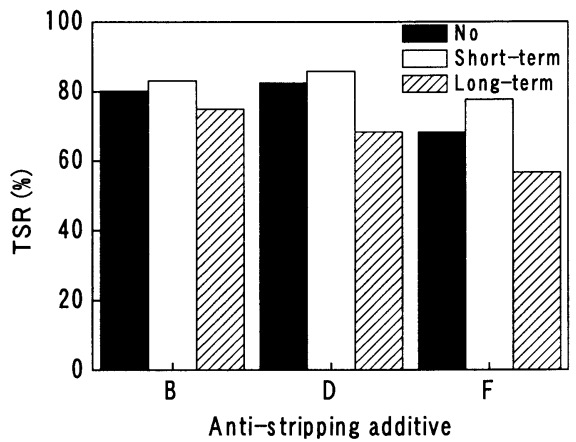

Figure 15 Influence of aging on TSR

Figure 9 shows the retained Marshall stability. From the figure, it is found that all the anti-stripping additives except Portland cement (A) have basically similar effects on improving the moisture susceptibility of asphalt mixtures. Thus, the retained Marshall stability test yields almost no difference even when the treatment method changes.

Figures 10 and 11 show the results of the immersed wheel tracking tests for granite and schist aggregates, respectively. From these figures, it is found that the rut depth increases with tracking cycles irrespective of aggregate type, and that the asphalt mixture with schist has better rutting and water resistance than that with granite.

Figure 12 shows the rut depth at the end of the test. The asphalt mixtures with schist show smaller rut depth than those with granite, despite the larger number of tracking cycles. Lime, regardless of whether dry or slurry (B and C), remarkably improves the moisture stability of asphalt mixture. On the contrary, Portland cement (A) and liquid anti-stripping additives (D and $\mathrm{E}$ ) have less effect.

The stripping index SI indicates that lime slurry (C) can significantly improve the moisture susceptibility of asphalt mixture, as shown in Figure 13. Portland cement (A) has little effect as with rut depth. Thus, the results of the immersed 
wheel tracking test show the same influence of aggregate type on moisture susceptibility as the results of the Lottman test.

\section{(2) Influence of aging method on moisture susceptibility}

Figure 14 shows the retained Marshall stability test results of limestone asphalt mixture. The retained Marshall stability for each anti-stripping additive decreases with the aging process. As to the difference in the retained Marshall stability among the anti-stripping additives, it is clear without aging, while it becomes imperceptible after long-term aging.

Figure 15 shows TSR in the Lottman test for limestone asphalt mixture. TSR values increase after short-term aging irrespective of treatment type, due to stiffening of the asphalt concrete with aging, but decrease after long-term aging. It is also found that lime (B) is more effective than the liquid antistripping additive (D) even after long-term aging. Thus, the Lottman test would be more useful than the retained Marshall stability test in evaluating the moisture susceptibility.

\section{SUMMARY AND CONCLUSION}

A series of laboratory tests was conducted to evaluate the moisture susceptibility of asphalt mixtures and the effectiveness of anti-stripping additives. The following conclusions were drawn.

1. Both the asphalt and aggregate types have dominating influences on the asphalt-aggregate bond and moisture susceptibility of asphalt mixtures.

2. Asphalt acid value can be used to evaluate the moisture susceptibility of asphalt mixtures; the moisture stability increases with asphalt acid value.

3. Limestone has superior stripping resistance and schist has marginally higher stripping resistance than granite.

4. The net adsorption test is superior to the water immersion and electro-optic colorimetry test for evaluating asphalt-aggregate bond.

5. The treatment of asphalt mixtures with hydrated lime slurry is a more effective method for decreasing moisture susceptibility, in comparison with liquid anti-stripping additives and Portland cement.

6. The Lottman test and immersed wheel tracking tẹst are better than retained Marshall stability test for evaluating the moisture susceptibility of asphalt mixtures.

7. The moisture susceptibility of asphalt mixture with additives decreases with the aging process. The difference in the moisture susceptibility among the aggregates after long-term aging process could be evaluated by the Lottman test.

ACKNOWLEDGMENT: The authors would like to express sincere appreciation to JSPS for their support of this study.

\section{REFERENCES}

1) Kennedy, T.W.: Prevention of water damage in asphalt mixtures, ASTM, Special Technical Publication (STP), No.899, pp. 119-113, 1984.

2) Kennedy, T.W. and Ping, W.V.: Comparison study of moisture damage test methods for evaluating anti-stripping treatments in asphalt mixtures, Transportation Research Record (TRR), No. 1323, pp. 94-111, 1991.

3) Curtist, C.W., Lytton, R.L. and Brannan, C.J.: Influence of aggregate chemistry on the adsorption and desorption of Asphalt, TRR, No. 1362, pp. 1-9, 1992.

4) Curtis, C.W., Stroup-Gardiner, M., Brannan, C.J. and Jones IV, D.R.: Net adsorption of asphalt on aggregate to evaluate water sensitivity, TRR, No. 1362, pp. 10-19, 1992.

5) Stroup-Gardiner, M. and Epps, J.A.: Four variables that affect the performance of lime in asphalt aggregate mixtures, TRR, No.1115, pp. 12-22, 1987.

6) Little, D.N. and Epps, J.A.: The benefits of hydrated lime in hot mix asphalt, national lime association, 48p., 2001.

7) Kennedy, T.W. et al.: Evaluation of methods for field applications of lime to asphalt mixture, Association of Asphalt Paving Technologists, Vol. 52, pp. 508-529, 1983.

8) Button, J.W.: Maximizing the beneficial effects of lime in asphalt paving mixtures, ASTM, STP, No.899, pp. 134$146,1984$.

9) Sebaaly, P.E., et al.: Performance of lime in hot mix asphalt mixtures, university of Nevada Reno, Research Report No. 1358-2, 2001.

10) Selim, A.A.: Liquid anti-stripping agents can be advantageous over hydrated lime in resisting moistureinduced damage in asphalt mixtures, Fifth International Conference on the Bearing Capacity of Roads and Airfields, pp. 1173-1182, 1998.

11) The test specifications of asphalt and asphalt mixture, Press of People Communication, 2000 (in Chinese).

12) Japan Highway Public Corporation: Test method of Japan Highway Public Corporation, 1992 (in Japanese).

13) Harrigan, E.T., Leahy, R.B. and Youtcheff, J.S.(eds.): The SUPERPAVE Mix Design System Manual of Specifications, Test Methods, and Practices, SHRP, A-379, pp.87-94, 1994.

14) Walsh, G., Mahony, M.O. and Jamieson, I.L.: Net adsorption test for chip-sealing aggregate and binders, TRR, No. 1507, pp. 1-12, 1995.

15) Kandhal, P.S.: Field and Laboratory Investigation of Stripping in Asphalt Pavements: State of the Art Report, TRR, No.1454, pp.36-47,1994.

(Received January 31, 2003) 